\title{
The death-associated protein DAXX is a novel histone chaperone involved in the replication-independent deposition of $\mathrm{H} 3.3$
}

\author{
Pascal Drané, ${ }^{1}$ Khalid Ouararhni, Arnaud Depaux, Muhammad Shuaib, and Ali Hamiche ${ }^{2}$ \\ IGMBC (Institut de Génétique et de Biologie Moléculaire et Cellulaire), Illkirch F-67400, France; CNRS, UMR7104, Illkirch \\ F-67404, France; Inserm, U964, Illkirch F-67400, France; and Université de Strasbourg, Strasbourg F-67000, France
}

\begin{abstract}
The histone variant H3.3 marks active chromatin by replacing the conventional histone H3.1. In this study, we investigate the detailed mechanism of $\mathrm{H} 3.3$ replication-independent deposition. We found that the death domainassociated protein DAXX and the chromatin remodeling factor ATRX ( $\alpha$-thalassemia/mental retardation syndrome protein) are specifically associated with the $\mathrm{H} 3.3$ deposition machinery. Bacterially expressed DAXX has a marked binding preference for $\mathrm{H} 3.3$ and assists the deposition of $(\mathrm{H} 3.3-\mathrm{H} 4)_{2}$ tetramers on naked DNA, thus showing that DAXX is a H3.3 histone chaperone. In DAXX-depleted cells, a fraction of H3.3 was found associated with the replication-dependent machinery of deposition, suggesting that cells adapt to the depletion. The reintroduced DAXX in these cells colocalizes with H3.3 into the promyelocytic leukemia protein (PML) bodies. Moreover, DAXX associates with pericentric DNA repeats, and modulates the transcription from these repeats through assembly of H3.3 nucleosomes. These findings establish a new link between the PML bodies and the regulation of pericentric DNA repeat chromatin structure. Taken together, our data demonstrate that DAXX functions as a bona fide histone chaperone involved in the replication-independent deposition of H3.3.
\end{abstract}

[Keywords: Histone variant; H3.3; histone chaperone; PML-NBs]

Supplemental material is available at http://www.genesdev.org.

Received November 10, 2009; revised version accepted April 15, 2010.

In addition to the conventional core histones, cells express low amounts of their nonallelic isoforms, the histone variants. The replacement of major histones by histone variants has emerged as an important way to control chromatin function by altering the biochemical makeup of the nucleosome (Kamakaka and Biggins 2005).

One of the best-studied histone variants is H3.3, which can replace the major species, H3.1. Although H3.1 and H3.3 are $96 \%$ identical, they exhibit important differences in behavior. H3.1 is synthesized in S phase and is deposited only during DNA replication. In contrast, H3.3 is expressed throughout the cell cycle and is incorporated at all phases of the cell cycle (Ahmad and Henikoff 2002a). Initial experiments performed in Drosophila showed that the deposition of H3.3 into chromatin appeared to be coupled to transcription (Ahmad and Henikoff 2002b; Schwartz and Ahmad 2005). Detailed analysis of H3.3 distribution pat-

${ }^{1}$ Present address: Institut Andre Lwoff, CNRS FRE 2944, 94800 Villejuif, France.

${ }^{2}$ Corresponding author.

E-MAIL hamiche@igbmc.u-strasbg.fr; FAX 33-3-88-65-32-01.

Article published online ahead of print. Article and publication date are online at http://www.genesdev.org/cgi/doi/10.1101/gad.566910. terns has revealed that both promoter remodeling and transcription elongation could be involved in the deposition of this variant (Chow et al. 2005; Mito et al. 2005; Wirbelauer et al. 2005). Consequently, H3.3 was proposed to be a marker of active chromatin and to be associated with the epigenetic maintenance of chromatin status (Henikoff et al. 2004; Ng and Gurdon 2008). This hypothesis is supported by the finding that H3.3 is enriched in post-translational modifications specific for active genes (McKittrick et al. 2004; Hake et al. 2006). Additionally, H3.3-containing nucleosomes are intrinsically less stable than those containing H3.1 (Jin and Felsenfeld 2007). This might facilitate the transcription by reducing the energy required to evict nucleosomes from active genes, and provide for the quick removal of existing epigenetic marks. Purification of the complexes responsible for the H3.1 and H3.3 deposition from epitope-tagged H3-expressing HeLa cell lines has revealed that these histones associate with distinct chromatin assembly complexes (Tagami et al. 2004). H3.1 was found mainly within a complex containing the replication-dependent Chromatin Assembly Factor 1 (CAF-1), whereas H3.3 copurified with a complex containing the HIRA protein (Tagami et al. 2004). 
The HIRA protein is believed to be a specific H3.3 chaperone able to deposit H3.3 independently of DNA synthesis (Tagami et al. 2004). The available data suggest that HIRA is involved in the deposition of H3.3 during decondensation of the Drosophila sperm pronucleus (Loppin et al. 2005). However, HIRA is not required for this deposition in embryos or in adult tissues (Loppin et al. 2005; Bonnefoy et al. 2007). In contrast, the chromatin remodeling factor $\mathrm{CHD} 1$ was found to deposit $\mathrm{H} 3.3$ not only in the Drosophila male pronucleus, but also during later stages of embryonic development (Konev et al. 2007). This supports the view that multiple and possibly redundant pathways are involved in the assembly of H3.3 nucleosomes.

In this study, we reinvestigated the mechanism that governs $\mathrm{H} 3.3$ deposition by purifying the $\mathrm{H} 3.3$-containing complexes from HeLa cells. Unexpectedly, we found that human HIRA did not form a stable complex with H3.3. Instead, our data identify HIRA as a member of a histoneless complex closely related to the previously described yeast HIR complex (Green et al. 2005). We show that the death domain-associated protein DAXX and the chromatin remodeling factor ATRX $(\alpha$-thalassemia/mental retardation syndrome protein) are associated with the H3.3 preassembly complex. In addition, DAXX colocalizes with H3.3 into promyelocytic leukemia protein nuclear bodies (PML-NBs) and regulates the expression of mouse pericentric DNA repeats. We further present evidence that DAXX is a bona fide histone chaperone specific for H3.3.

\section{Results}

\section{Isolation of H3.1 and H3.3 nucleosome preassembly complexes and identification of specific partners}

We used the double-immunoaffinity purification method (Nakatani and Ogryzko 2003; Tagami et al. 2004; Ouararhni et al. 2006) to isolate the H3.1 and H3.3 nucleosome preassembly complexes. Histones H3.1 and H3.3 were expressed stably as fusion proteins with C-terminal Flag- and HA-epitope tags in HeLa cells (Fig. 1A). Epitope-tagged H3.1 and H3.3 (e-H3.1 and e-H3.3) nucleosome preassembly complexes were then purified from nuclear-soluble extracts by sequential immunoprecipitations with antiFlag antibody, followed by anti-HA antibody (Ouararhni et al. 2006). Proteins associated with e-H3.1 and e-H3.3 nuclear complexes (NCs) were separated by SDS-containing $4 \%-12 \%$ polyacrylamide gradient gels and silver-stained (Fig. 1B). Numerous proteins were found to be associated physically with e-H3.1 and e-H3.3 (Fig. 1B). Mass spectrometry and immunoblotting analysis allowed the identification of the following partners as components common to the e-H3.1 and e-H3.3 complexes: core histones (H2A, H2B, H3, and H4), several well-characterized histone chaperones (anti-silencing factor 1a[ASF1a] and ASF1b, nuclear autoantigenic sperm protein [tNASP and the shorter form, sNASP] and p46/p48), histone acetyltransferase 1 (HAT1), Ku proteins (Ku70 and Ku80), Importin4, PARP-1, Topoisomerase II (TOP2), and DNA-dependent protein kinase (DNA-PK).
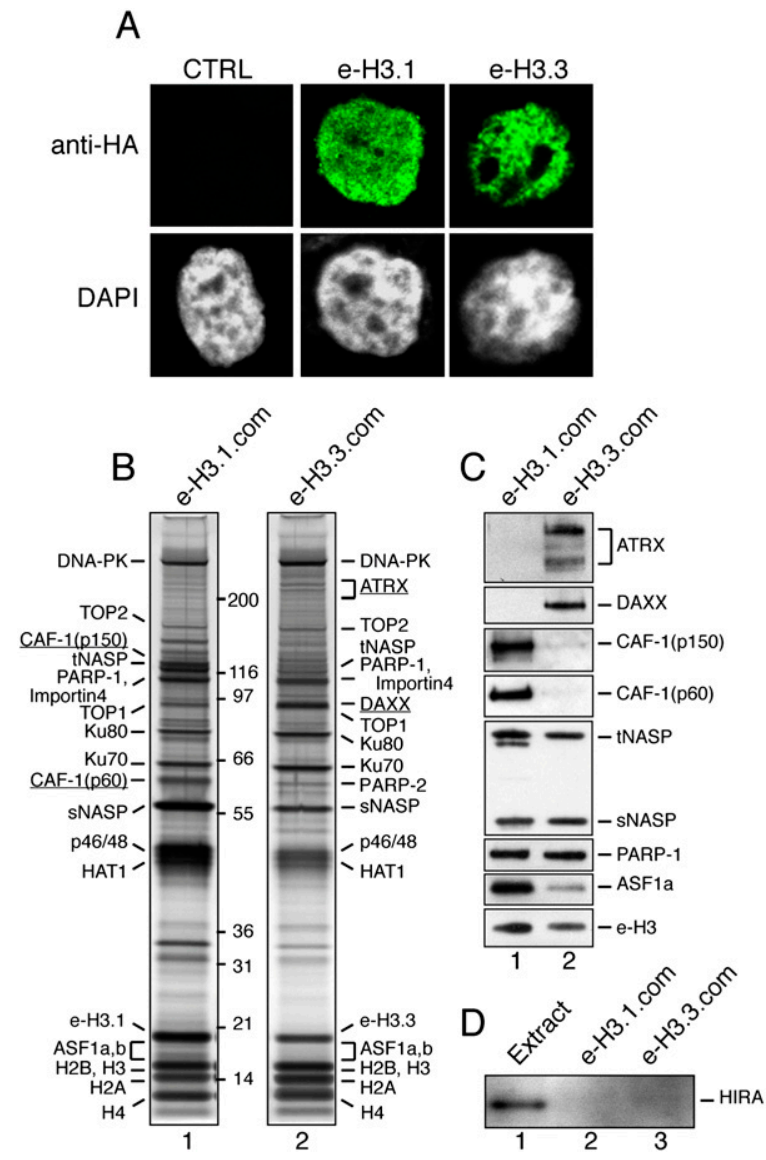

Figure 1. Immunopurification of e-H3.1 and e-H3.3 deposition complexes from soluble nuclear fractions. (A) Stable expression of e-H3.1 and e-H3.3 in HeLa cells. Cells expressing e-H3.1 or e-H3.3 and control cells (CTRL) were stained with anti-HA (top) and DAPI (bottom). (B) Silver staining of proteins associated with e-H3.1 (lane 1) and e-H3.3 NCs (lane 2). The complexes containing e-H3.1 (e-H3.1.com) and e-H3.3 (e-H3.3.com) were purified by double immunoaffinity from soluble nuclear extracts (NCs). Polypeptides identified by mass spectrometry analysis and the positions of molecular size markers are indicated. $(C)$ DAXX and ATRX proteins are specific to the e-H3.3 NC. The e-H3.1 (lane 1) and e-H3.3 (lane 2) complexes were analyzed by immunoblotting with the indicated antibodies. $(D)$ HIRA is not associated with H3.3. The e-H3.1 (lane 2) and e-H3.3 (lane 3) NCs were analyzed by immunoblotting with anti-HIRA antibody. (Lane 1) HeLa whole-cell extract was used as a control.

Two of the three CAF-1 subunits (p150 and p60) were highly specific to the e-H3.1 complex, whereas the third CAF-1 subunit (p46/p48) was a component common to e-H3.1 and e-H3.3 complexes (Fig. 1B,C). This corroborated the reported data, showing that the CAF-1 subcomplex is part of the e-H3.1-containing complex (Tagami et al. 2004).

Concerning the specific partners of H3.3, HIRA was detected within the H3.3 complex after the first anti-Flag affinity (Supplemental Fig. 1), but was undetectable by mass spectrometry or by immunoblotting analysis after the second anti-HA affinity (Fig. 1B,D). We excluded the possibility that loss of HIRA after the anti-HA affinity step was due to an inefficient HA elution (see Supplemental 
Fig. 2). This indicates that HIRA is not a stable component of the e-H3.3 complex. In contrast, after the doubleimmunoaffinity purification, we identified DAXX (originally found associated with CD95) (Yang et al. 1997) and ATRX (a member of the SNF2 family of chromatin remodeling factors) (Steensma et al. 2005) within the H3.3 complex, but not in the H3.1 complex (Fig. 1B). Immunoblotting of the purified complexes confirmed that both proteins were present only within the e-H3.3 complex (Fig. 1C).

\section{DAXX is a stable component of e-H3.3-nucleosome preassembly complexes}

DAXX is an acidic protein (pI 4.6) containing a stretch rich in glutamic and aspartic acid residues embedded within a yeast histone chaperone, Rtt106-like domain (Fig. 3A [below]; Supplemental Fig. 3). This raised the possibility that DAXX acts as a chaperone specific for H3.3. If this is the case, DAXX should interact strongly with $\mathrm{H} 3.3$ both in vitro and in vivo. With this in mind, we first checked that DAXX was stably associated with the H3.3 complex in vivo. To this end, isolated $\mathrm{H} 3.1$ and $\mathrm{H} 3.3$ complexes from nuclear-soluble extracts were fractionated on glycerol gradients. The different fractions were then run on a denaturing $4 \%-12 \%$ gradient gel, and proteins were silverstained. Two distinct subcomplexes with different molecular masses were identified in both H3.1 and H3.3 NCs (Fig. 2A,B). These subcomplexes were termed LNC (for low-molecular-weight NC) and HNC (for high-molecularweight NC). In parallel, e-H3.3 and e-H3.1 complexes were also purified from the cytosolic fractions $(\mathrm{CC}$, for cytosolic complex) (Fig. 2C).

Immunoblotting analysis revealed that DAXX and ATRX were present within both the nuclear (LNC and $\mathrm{HNC}$ ) and the cytosolic (CC) e-H3.3 subcomplexes (Fig. 2D), whereas CAF-1 p150 and p60 were detected only within the nuclear (LNC and HNC) e-H3.1 subcomplexes (Fig. 2D). NASP and ASF1 histone chaperones were common to both complexes (e-H3.3/e-H3.1), and were distributed within CC and LNC subcomplexes, but not in the corresponding HNC subcomplexes (Fig. 2C,D). Mass spectrometry and immunoblotting analysis revealed that the ASF1-containing complexes (CC and LNC) comprised e-H3.3-H4 or e-H3.1-H4, but not the other core histones (including the untagged endogenous histone $\mathrm{H} 3.3 / \mathrm{H} 3.1$ ) (Fig. 2C; data not shown). This is consistent with the available data suggesting an interaction of ASF1 with one $\mathrm{H} 3-\mathrm{H} 4$ heterodimer by competing for the same surface of interaction that is normally occupied by the second $\mathrm{H} 3-\mathrm{H} 4$ dimer in the tetrameric complex (English et al. 2006; Agez et al. 2007; Natsume et al. 2007). In contrast, ASF1-free HNC complexes comprised the four core histones (including endogenous $\mathrm{H} 3.3$ and $\mathrm{H} 3.1$ ), suggesting that $\mathrm{HNC}$ complexes contained either histone octamers or heterotypic tetramers (H2A, H2B, H3, and H4) (Fig. 2C; Supplemental Fig. 4). To rule out the possibility that $\mathrm{H} 2 \mathrm{~A}-\mathrm{H} 2 \mathrm{~B}$ dimers derive from contaminating chromatin, the e-H3.3 complex was treated with DNase I or ethidium bromide. The presence of the four core histones within the H3.3 complex was insensitive to both treatments, and conse- quently was not mediated by DNA (Supplemental Fig. 5). This observation raised interesting questions about the mechanism of histone deposition (see the Discussion).

In summary, these data demonstrate that (1) DAXX is a stable component of cytoplasmic and nuclear e-H3.3-containing complexes, but not of e-H3.1-containing complexes; and (2) a fraction of e-H3.3 or e-H3.1 contains the four core histones, and is present within an ASF1-free complex.

\section{DAXX interacts directly and preferentially} with $H 3.3$ both in vitro and in vivo

We next investigated whether DAXX interacted directly with H3.3 in vitro using a GST pull-down assay. Purified GST-DAXX fusion protein was immobilized on glutathione-agarose beads and incubated with recombinant histone tetramers H3.1-H4 or H3.3-H4 (Fig. 3B). Bead-bound complexes were next washed with the indicated $\mathrm{NaCl}$ concentration, eluted, and fractionated on SDS-PAGE. Coomassie blue staining revealed that $\mathrm{H} 3.3-\mathrm{H} 4$ exhibited a more robust interaction (persisting at higher ionic strength) with GST-DAXX protein than H3.1-H4 (Fig. 3B, cf. lanes 3-5 and 7-9). This demonstrated that DAXX associates preferentially with H3.3. Similar results were obtained using native histones purified from chromatin of HeLa cells stably expressing e-H3.1 or e-H3.3 instead of recombinant histones (Supplemental Fig. 6).

To determine the region of DAXX involved in the recognition of $\mathrm{H} 3.3$, we generated deletion mutants containing either the N-terminal (1-302), central (302-495), or C-terminal (495-740) domain of DAXX. We expressed these mutants as GST fusion proteins and examined their binding to native e-H3.3-H4 histones. Immunoblotting using an anti-HA antibody revealed that the acidic central domain, containing the Rtt106-like motif, exhibited a strong interaction with e-H3.3-H4 (Fig. 3C). Note that the $\mathrm{N}$-terminal domain of DAXX also interacted with histones, but to a lesser extent than did the central domain (Fig. 3C).

To further investigate the preferential binding of DAXX to H3.3 in a more physiological context, DAXX was stably expressed in HeLa cells as a fusion protein with C-terminal Flag- and HA-epitope tags. e-DAXX complex was purified using the same procedure described for e-H3.3. Mass spectrometry analysis identified ATRX as a partner of e-DAXX in both the CC and the NC fractions (Fig. 3D), as found previously by others using different approaches (Xue et al. 2003; Tang et al. 2004). In addition, both complexes contained p46/p48, TBA2 (Tubilin $\alpha 2$ ), UBP7, Agrin (Fig. 3D), and histones $\mathrm{H} 3$ and $\mathrm{H} 4$, but not ASF1 or NASP, two chaperones identified within e-H3.3 complex (Fig. 3D; Supplemental Fig. 7). We next performed a more detailed analysis to determine the precise nature of the $\mathrm{H} 3$ copurified with e-DAXX (i.e., H3.3 vs. other H3 isoforms). Mass spectrometry analysis identified several peptides corresponding exclusively to H3.3 (Supplemental Fig. 8). This result was then confirmed by immunoblotting using a specific antibody directed against H3.3 (Fig. 3E; Supplemental Fig. 9). Together, these data established that DAXX binds H3.3 preferentially in vivo (compared with H3.1) and could 
A - e-H3.1.com

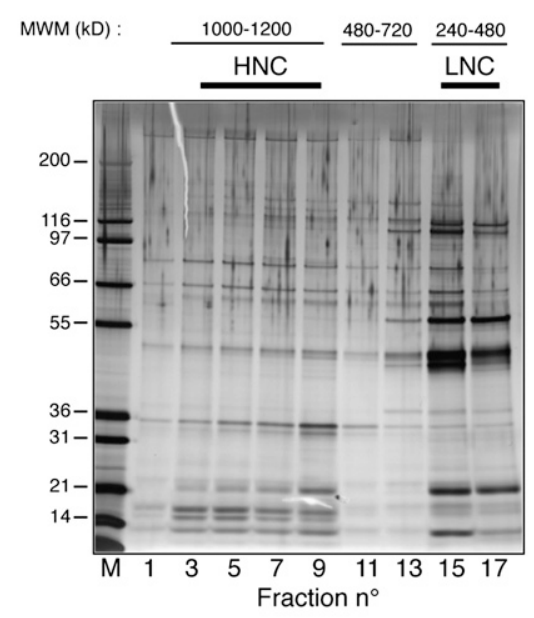

B - e-H3.3.com

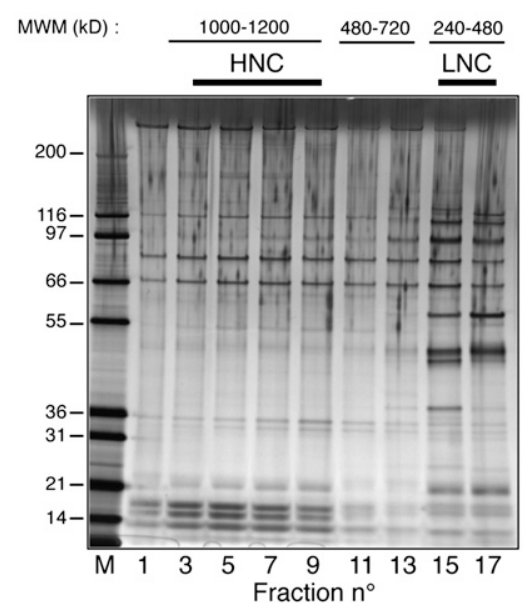

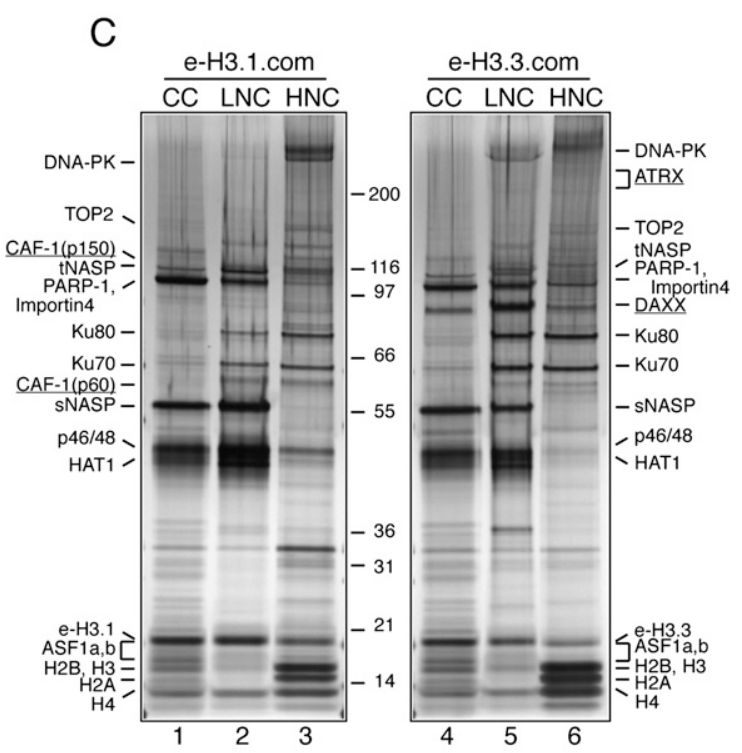

$\mathrm{D}$

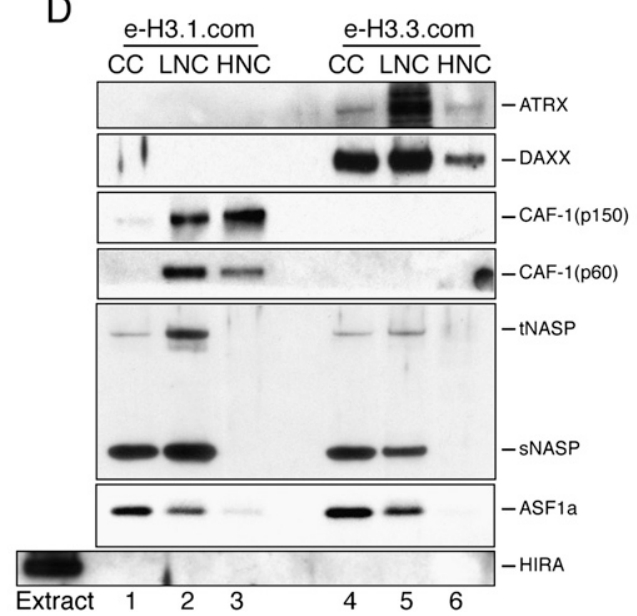

Figure 2. DAXX is stably associated with the H3.3, but not with the H3.1 complex. (A) Silver staining of nuclear e-H3.1 complex fractionated on a glycerol gradient. The e-H3.1 NC purified by double affinity was separated on a glycerol gradient. Fractions were pooled as indicated at the top of the gel. The approximate molecular weight of the different subcomplexes was estimated using the NativeMark molecular weight marker (MWM; Invitrogen). (B) Silver staining of nuclear e-H3.3 complex fractionated on a glycerol gradient. Experiments were performed as described in $A$. $(C)$ Silver staining of pooled fractions containing e-H3.1 and e-H3.3 nuclear subcomplexes (LNC and HNC) and of e-H3.1 and e-H3.3 CCs. (D) Immunoblotting of pooled fractions containing e-H3.1 and e-H3.3 nuclear subcomplexes (LNC and HNC) and of e-H3.1 and e-H3.3 CCs with the indicated antibodies. Input fraction (extract) is shown for the blot with anti-HIRA.

explain why DAXX was found only in e-H3.3 complex (see Fig. 1A).

\section{HIRA does not form a stable complex with H3.3 in HeLa cells}

To gain insight into the relationship between HIRA and H3.3, a HeLa cell line stably expressing a Flag- and HAtagged version of HIRA was generated (e-HIRA). Cabin1, Ubinuclein1, the hypothetical protein FLJ25778, ASFla, and ASF1b were identified by mass spectrometry analysis as major components of the e-HIRA complex (Fig. 3D; Supplemental Fig. 7). Cabin1 has been characterized recently as a candidate human ortholog of Hir3, a component of the yeast HIR complex (Balaji et al. 2009). Ubinuclein1 and FLJ25778 (termed also Ubinuclein2) were also proposed to be candidate orthologs of another component of the yeast HIR complex, Hpc2 (Banumathy et al. 2009). Together, these data would imply that the HIRA/ASF1 complex is conserved through evolution. However, in contrast to the yeast HIR complex (Green et al. 2005), the e-HIRA complex did not contain histones (Fig. 3D,E). This is entirely consistent with our data showing that HIRA is not a stable component of the e-H3.3-containing complex (see the Discussion; Fig. 1B,D). 


\section{A - DAXX structure}
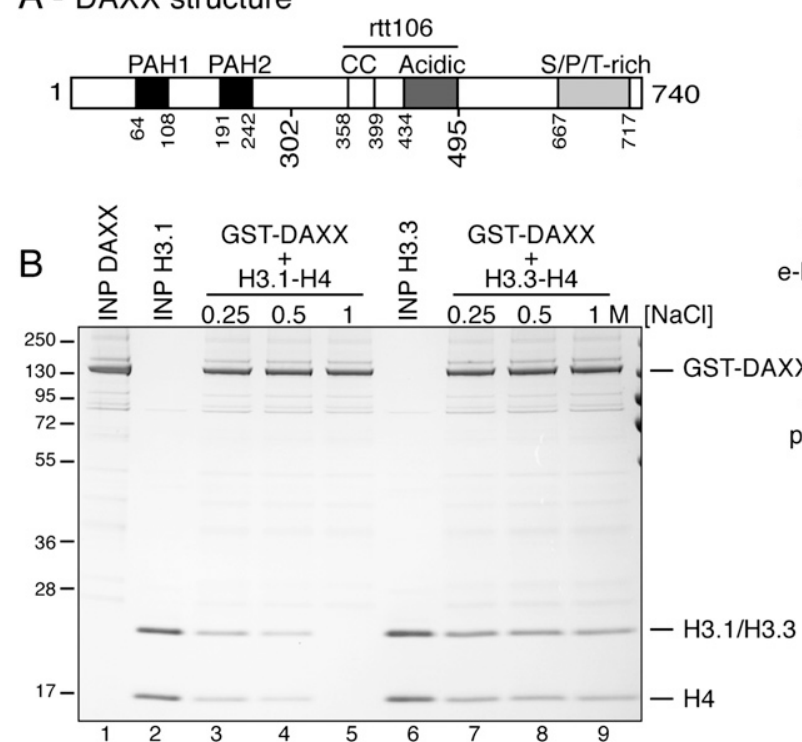

C

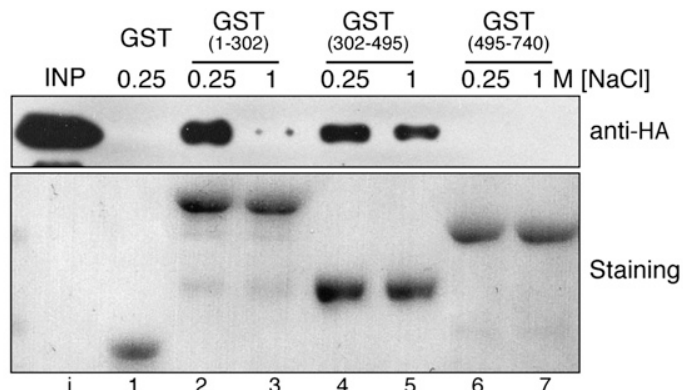

$\mathrm{D}$

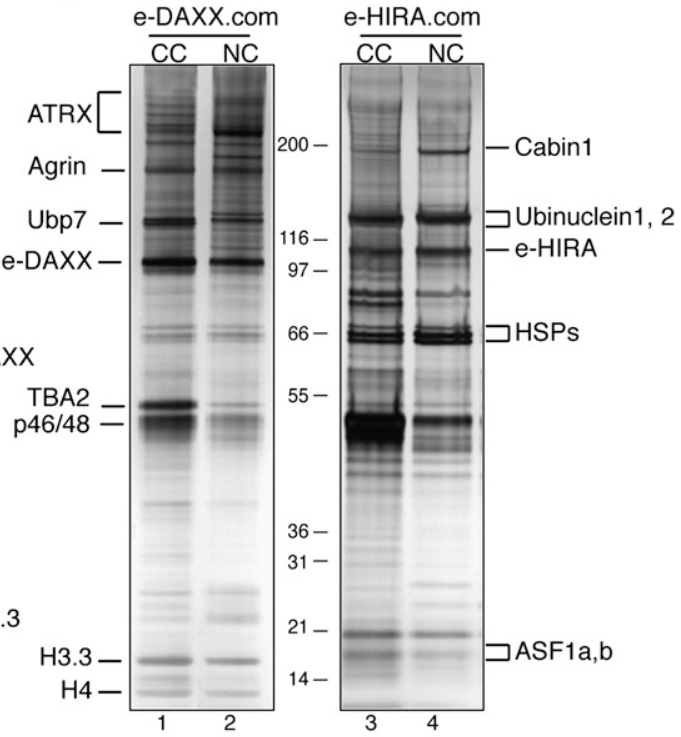

E

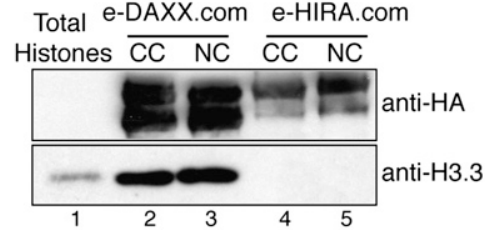

Figure 3. DAXX preferentially associates with H3.3 in vitro and in vivo. (A) Primary structure of DAXX. DAXX contains several putative domains: two paired amphipathic helices (PAH1 and PAH2), a coiled-coil (CC), an acidic domain (acidic), a Ser/Pro/Thr rich domain (S/P/T-rich), and an rtt106-like domain (rtt106). (B) DAXX preferentially associates with H3.3 in vitro. GST-DAXX, immobilized on glutathione-agarose, was incubated with recombinant histones H3.1-H4 (lanes 3-5) or H3.3-H4 (lanes 7-9). Bead-bound complexes were washed with the indicated concentration of $\mathrm{NaCl}$. Eluted proteins were fractionated on SDS-PAGE and stained with colloidal blue. The input lanes (INP) represent the amount of proteins used for the pull-down. (C) The central part of DAXX contains a high affinity H3.3-interacting domain. N-terminal (1-302), central (302-495), and C-terminal (495-740) regions of DAXX were produced as GST fusion proteins. The fusion proteins (lanes 2-7) and GST alone (lane 1), immobilized on glutathione-agarose resin, were incubated with tetramers containing epitope-tagged H3.3. (Top) After washing with either 0.25 or $1 \mathrm{M} \mathrm{NaCl}$, the resin-bound tetramers were analyzed by immunoblotting using anti-HA antibody. (Bottom) To compare the levels of the GST fusions used for the pull-down, the blot was first stained with Ponceau red. The input lane (i) represents $40 \%$ of the amount of tetramers used for the pulldown. $(D)$ Silver staining of DAXX and HIRA complexes (e-DAXX.com and e-HIRA.com) purified by double immunoaffinity from either cytoplasmic extract $(\mathrm{CC})$ or soluble nuclear extract $(\mathrm{NC})$. The polypeptides identified by mass spectrometry analysis are indicated. $(E)$ The DAXX complex, but not the HIRA complex, contains H3.3. The e-DAXX (lanes 2,3) and e-HIRA (lanes 4,5) complexes were analyzed by immunoblotting with anti-HA (top) and anti-H3.3 (bottom) antibodies. (Lane 1) Total histones purified from HeLa cells were used as control.

\section{DAXX facilitates the deposition of H3.3 in vitro}

Acidic domains are known to bind basic proteins such as histones and to mediate nucleosome assembly (De Koning et al. 2007). We tested whether DAXX was able to assist the deposition of histones on DNA and to assemble a functional $(\mathrm{H} 3.3-\mathrm{H} 4)_{2}$ tetrameric particle (tetrasome). Labeled 359-base-pair (bp) DNA encompassing the Drosophila Hp70A promoter (Hamiche et al. 1999) was circularized under conditions that generate one negative supercoil corresponding to topoisomer -1 . This negatively supercoiled DNA has been shown previously to be a very good substrate for histone $(\mathrm{H} 3-\mathrm{H} 4)_{2}$ deposition, and allows a clear in-gel visualization of tetrasome formation (Hamiche and Richard-Foy 1999). The negatively supercoiled DNA was then incubated with increasing amounts of $\mathrm{H} 3.3-\mathrm{H} 4$ histones (at the indicated histone/DNA ratio, rw), which were either preincubated or not with equimolar amounts of DAXX for $30 \mathrm{~min}$ (Fig. 4A); then the deposition of histones onto DNA was analyzed by EMSA (Fig. 4B). Under 


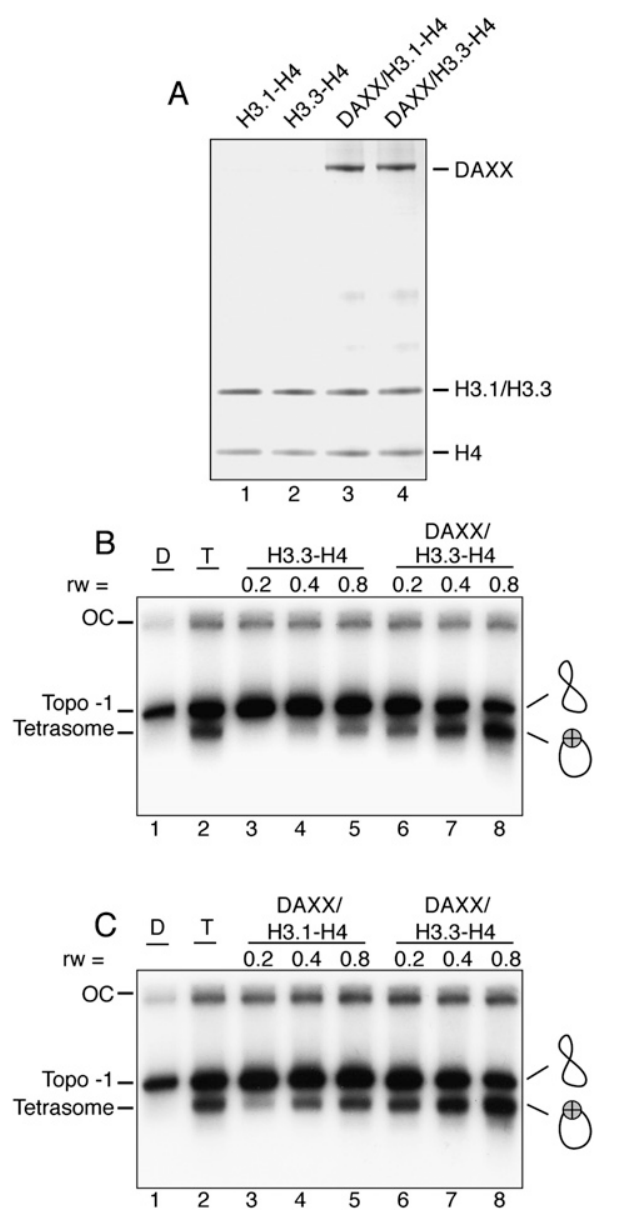

Figure 4. DAXX favors deposition of $\mathrm{H} 3.3$ in vitro. $(A)$ Purification and reconstitution of recombinant DAXX/histone complex. Histones H3.1-H4 (lane 1) or H3.3-H4 (lane 2) and full-length DAXX were expressed in bacteria and mixed at equimolar ratio (lanes 3,4). (B) DAXX facilitates the deposition of $(\mathrm{H} 3.3-\mathrm{H} 4)_{2}$ tetramers on DNA. Negatively supercoiled DNA corresponding to topoisomer -1 was incubated with increasing amounts of $(\mathrm{H} 3.3-\mathrm{H} 4)_{2}$ tetramers (at the indicated histone/DNA ratio, rw) either in the presence (lanes 6-8) or the absence (lanes 3-5) of equimolar (to the tetramers) amounts of GST-DAXX. The reaction products were then analyzed on native $4.5 \%$ polyacrylamide gel. (Lane 1) Topoisomer -1 DNA. (Lane 2) $(\mathrm{H} 3.3-\mathrm{H} 4)_{2}$ tetrasomes reconstituted on topoisomer -1 by salt dialysis. Positions of the open circular DNA (OC), the naked topoisomer -1 DNA, and the $(\mathrm{H} 3.3-\mathrm{H} 4)_{2}$ tetrasome are indicated. (C) DAXX deposits more efficiently $(\mathrm{H} 3.3-\mathrm{H} 4)_{2}$ than $(\mathrm{H} 3.1-\mathrm{H} 4)_{2}$ tetramers. Topoisomer -1 was incubated with increasing amounts (at the indicated histone/

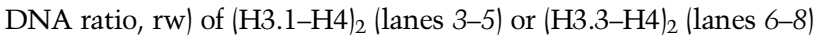
tetramers in the presence of equimolar (to the tetramers) amounts of GST-DAXX. The reaction products were then analyzed on native $4.5 \%$ polyacrylamide gel. (Lane 1) Topoisomer -1 DNA. (Lane 2) (H3.3-H4) 2 tetrasomes reconstituted on topoisomer -1 by salt dialysis. Positions of the open circular DNA $(\mathrm{OC})$, the naked topoisomer -1 DNA, and the $(\mathrm{H} 3.3-\mathrm{H} 4)_{2}$ tetrasome are indicated.

these conditions (in the absence of DAXX), very low amounts of $(\mathrm{H} 3.3-\mathrm{H} 4)_{2}$ tetramer deposition were observed (Fig. 4B, lanes 3-5). However, in the presence of DAXX, a significant deposition of $(\mathrm{H} 3.3-\mathrm{H} 4)_{2}$ tetramers was visualized by EMSA (Fig. 4B, lanes 6-8). This shifted complex comigrated with $(\mathrm{H} 3.3-\mathrm{H} 4)_{2}$ particles reconstituted by dialysis (Fig. 4B, lane 2). The DAXX-mediated deposition of histones on DNA is more efficient compared with what could be obtained by the salt dialysis method.

As a control, we also assayed the ability of DAXX to favor the deposition of H3.1-H4. In contrast to what was observed with H3.3-H4 (Fig. 4B), DAXX poorly favored the deposition of H3.1-H4 (Supplemental Fig. 10). This finding suggested that H3.3 is the preferred substrate of DAXX. To further prove this, increasing amounts of $(\mathrm{H} 3.1-\mathrm{H} 4)_{2}$ or $(\mathrm{H} 3.3-\mathrm{H} 4)_{2}$ tetramers, preincubated with equimolar amounts of DAXX (Fig. 4A), were incubated with DNA topoisomer -1 for $30 \mathrm{~min}$, and then the histone deposition was analyzed by EMSA (Fig. 4C). Under these conditions, very low amounts of $(\mathrm{H} 3.1-\mathrm{H} 4)_{2}$ tetramer deposition were observed (Fig. 4C, lanes 3-5), compared with amount of deposited (H3.3-H4) 2 (Fig. 4C, lanes 6-8). We conclude that DAXX is a histone chaperone specific for H3.3.

\section{Distinct H3.3 deposition mechanism operates in the absence of DAXX}

To further investigate the role of DAXX in the deposition of H3.3, we stably expressed epitope-tagged H3.3 in wild-type and $\mathrm{DAXX}^{-1-}$ mouse embryonic fibroblasts (MEFs) (Ishov et al. 2004). Preliminary attempts revealed that e-H3.3 was still incorporated into chromatin in DAXX-deficient cells (Fig. 7 [below]; data not shown). This suggests that, in the absence of DAXX, another chaperone could be involved in the deposition of H3.3. In order to understand how H3.3 was deposited in the absence of DAXX, proteins associated with e-H3.3 were purified by the double-immunoaffinity method from soluble nuclear extracts of wild-type and DAXX $^{-1-}$ MEF cells (Fig. 5A). As expected for the wild-type MEF cells, DAXX and ATRX were identified among the proteins associated with e-H3.3 in mice (Fig. 5A,B), suggesting that the deposition machinery is conserved in mammals. Note that, again, HIRA was not detected within the partners of e-H3.3 (Fig. 5B).

The purification of e-H3.3-containing complex from $\mathrm{DAXX}^{-1-}$ MEF cells revealed an altered protein composition when compared with the wild-type complex (Fig. 5A). This complex did not contain ATRX (Fig. 5A,B), suggesting that anchorage of this protein to the e-H3.3 complex is mediated by DAXX. We also noticed an increase in the amount of the histone chaperone tNASP (Fig. 5B). Initially, this chaperone was found associated with linker histone H1 (Richardson et al. 2000). By coexpression of tNASP with $\mathrm{H} 3.3-\mathrm{H} 4$ (or $\mathrm{H} 3.1-\mathrm{H} 4$ ) in bacteria, we found that tNASP binds also H3/H4 histones (Supplemental Fig. 11), as suggested by others (Wang et al. 2008). More surprisingly, we could clearly identify within this complex the replication-dependent deposition factor CAF-1, as evidenced by mass spectrometry and Western blotting using antibodies against CAF-1 p150 and p60 (Fig. 5A,B). This suggested that, in the absence of DAXX, the CAF-1 complex associates with a fraction of H3.3. Note that the amount of expressed CAF-1 p150 in both wild-type and DAXX ${ }^{-/-}$ MEFs was identical (Supplemental Fig. 12), thus ruling out the possibility that a change in expression of this protein 


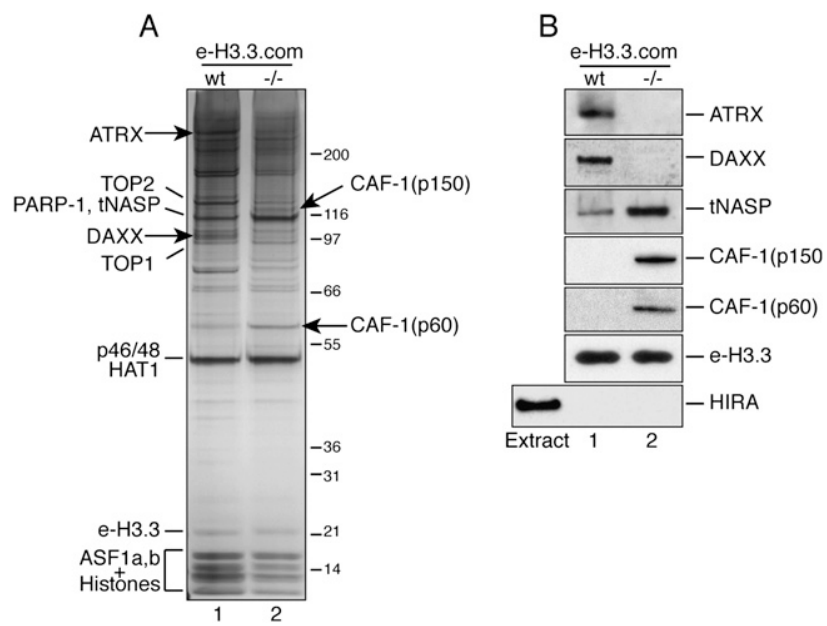

Figure 5. Purification of partners associated with e-H3.3 from extracts of stable wild-type and DAXX ${ }^{-/}$MEFs. (A) Silver staining of proteins associated with e-H3.3 from soluble nuclear extracts of stable wild-type (lane 1) and DAXX ${ }^{-1-}$ (lane 2) MEFs. H3.3 complexes were purified by double immunoaffinity. The polypeptides identified by mass spectrometry analysis are indicated. Arrows show the positions of partners specific to each complex. (B) Analysis by immunoblotting of proteins associated with e-H3.3 from extracts of stable wild-type (lane 1) and DAXX ${ }^{-/-}$ (lane 2) MEFs using the indicated antibodies. Input fraction (extract) is shown for the blot with anti-HIRA.

might be responsible for its recruitment within the e-H3.3 complex in $\mathrm{DAXX}^{-/-}$cells. Together, these data imply that DAXX-deficient cells adapt to deposit H3.3 by using alternative mechanisms of deposition.

\section{DAXX and ATRX-dependent deposition of H3.3 in pericentric heterochromatin}

DAXX is a component of the PML-NBs and directly interacts with ATRX, which is highly enriched at pericentric heterochromatin in mammals (McDowell et al. 1999; Ishov et al. 2004). Consistent with this, our chromatin immunoprecipitation (ChIP) assays in MEF cells revealed that DAXX and ATRX were indeed strongly enriched on pericentric DNA repeats (major satellites) (Fig. 6A), and were only poorly detected on pseudoGAPDH, another heterochromatin loci (Supplemental Fig. 13).

Recent studies have shown that pericentric DNA repeats are highly transcribed in mice (Lu and Gilbert 2007). The abundance of transcripts encoded by pericentric DNA repeats was therefore monitored in wildtype and DAXX ${ }^{-1-}$ MEF cells. Real-time RT-PCR analysis revealed that these transcripts were more abundant in wild-type cells than in DAXX-deficient cells (Fig. 6B). Similarly, the knockdown of H3.3 (by a siRNA pool directed against the two $\mathrm{H} 3.3$ genes $\mathrm{H} 3.3 \mathrm{~A}$ and $\mathrm{H} 3.3 \mathrm{~B}$ ) or ATRX strongly affected the transcription from pericentric DNA repeats (Fig. 6C; Supplemental Fig. 14). Note that the ablation of HIRA expression did not affect the expression from these repeats (Supplemental Fig. 14).

The above data suggested that H3.3, DAXX, and ATRX assist the transcription from pericentric chromatin. We hypothesized that this might be achieved through the DAXX-dependent assembly of H3.3 nucleosomes on pericentromeric chromatin in a replication-independent manner. To test this, $\mathrm{DAXX}^{-/-}$MEF cells were first
A

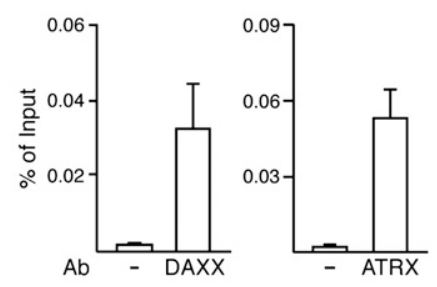

C

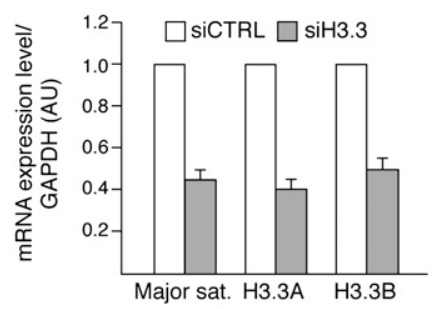

D

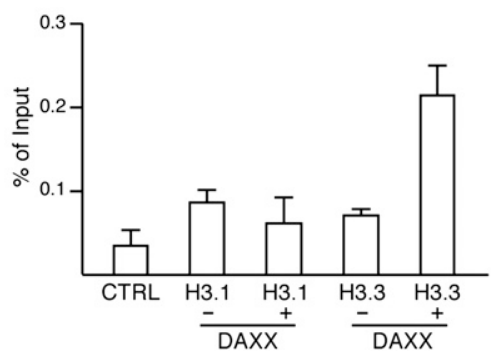

Figure 6. DAXX-dependent deposition of $\mathrm{H} 3.3$ on pericentric heterochromatin. (A) DAXX and ATRX are present on pericentric DNA repeats in wild-type MEFs. Presence of DAXX (left panel) and ATRX (right panel) on pericentric DNA repeats was investigated by ChIP assays using specific antibodies. $(-\mathrm{Ab})$ Control sample in which primary antibody was omitted. Results are expressed as percentage of chromatin input used for immunoprecipitation. $(B)$ The level of transcripts from pericentric DNA repeats is reduced in DAXX-deficient cells. Relative mRNA level for pericentric DNA repeats in wild-type and DAXX ${ }^{-1-}$ MEFs was determined by quantitative RT-PCR. Results are represented as relative expression level of pericentric DNA repeats versus $G A P D H$. Mean \pm standard deviation of four independent experiments. $(C)$ Depletion of $H 3.3 A$ and $H 3.3 B$ resulted in a decrease in transcription from pericentric DNA repeats. MEFs were transfected with control siRNA (siCTRL) or a mixture of $H 3.3 A$ and $H 3.3 B$ siRNA (siH3.3). Relative mRNA levels for pericentric DNA repeats, $H 3.3 A$, and $H 3.3 B$ were determined by quantitative RT-PCR. Results were normalized to GAPDH and were set at 1 in cells transfected with control siRNA. Mean \pm standard deviation of three independent experiments. $(D)$ DAXX is required for deposition of $\mathrm{H} 3.3$ onto pericentric DNA repeats outside of $S$ phase. DAXX ${ }^{-/-}$MEFs were deprived of serum for $48 \mathrm{~h}$ before being cotransfected with empty vector (CTRL) or else epitope-tagged H3.1 or H3.3 expression vector in combination with DAXX expression vector where indicated. Forty hours later, cells were reinduced for $8 \mathrm{~h}$ with $20 \%$ FCS in the presence of aphidicolin and were subjected to ChIP assays. Results are expressed as percentage of chromatin input immunoprecipitated. Mean \pm standard deviation of three independent experiments. 
synchronized in G0 by serum starvation, and then they were transfected with either e-H3.3 or e-H3.1 constructs (or empty vector as control) in combination or not with a HA-DAXX construct. Forty hours later, cells were supplemented with serum and left to progress through the cell cycle, reaching $S$ phase by $10 \mathrm{~h}$ after serum addition (data not shown). Before entry in S phase, the amounts of e-H3.1 and e-H3.3 integrated into pericentric repeats were evaluated by ChIP analysis $8 \mathrm{~h}$ after serum addition and in the presence of aphidicolin, an inhibitor of DNA polymerase. As expected, outside the S phase, e-H3.1 was poorly deposited on pericentric repeats even in the presence of DAXX (Fig. 6D). In the absence of DAXX, e-H3.3 was also poorly deposited. In contrast, addition of DAXX enhanced nearly threefold the e-H3.3 deposition in pericentric repeats (Fig. 6D). This stimulation was not due to an accumulation of e-H3.3 in DAXX-transfected cells, as verified by Western blot (data not shown). Moreover, we found that reduction of ATRX expression by siRNA led to a diminishment of DAXX-dependent deposition of H3.3 into pericentric repeats (Supplemental Fig. 14). In addition, the requirement of DAXX for H3.3 deposition seems to be restricted at least to pericentric DNA repeats, since H3.3 was deposited in the absence of DAXX at the active genomic site DHFR, although the presence of DAXX further increased H3.3 incorporation (Supplemental Fig. 13). Taken together, these results show that both DAXX and ATRX are required for H3.3 deposition onto pericentric DNA repeats outside the $S$ phase, and suggest that the DAXX/ATRX complex uses H3.3 to modulate the transcription from these repeats.

\section{$D A X X$ is essential for tethering H3.3 to PML-NBs}

A fraction of DAXX was found to accumulate in PML-NBs in the nucleus (Salomoni and Khelifi 2006). The PML-NBs form multiprotein structures where proteins accumulate and undergo post-translational modifications. These dotlike structures have been implicated in diverse biological functions, including the regulation of chromatin conformation (Bernardi and Pandolfi 2007). Interestingly, human pericentric DNA repeats can colocalize with DAXX within the PML-NBs (Luciani et al. 2006). Therefore, it is possible that DAXX, in addition to its role as a deposition factor, serves as a specific carrier that targets H3.3 to PML-NBs.

To study this possibility, resting $\mathrm{DAXX}^{-1-}$ MEFs were transiently transfected with a green fluorescence-tagged H3.3 (GFP-H3.3) in combination with a HA-DAXX construct or an empty vector as control (Fig. 7). After $40 \mathrm{~h}$, cells were reinduced for $8 \mathrm{~h}$ by serum addition in the presence of aphidicolin. Finally, cells were stained with DAPI and analyzed for the distribution of GFP-H3.3, DAXX, and PML in G1 phase. In the absence of DAXX (Fig. 7i-p), GFP-H3.3 showed a diffuse nuclear staining. The reintroduction of DAXX into the knocked-down cells resulted in a nice nuclear colocalization of $\mathrm{H} 3.3$ with DAXX and PML in a dot-like manner (Fig. 7a-h). We conclude that DAXX targets H3.3 to PML-NBs, suggesting a direct link between the accumulation of DAXX into PML-NBs and the deposition of $\mathrm{H} 3.3$ onto pericentric DNA repeats.

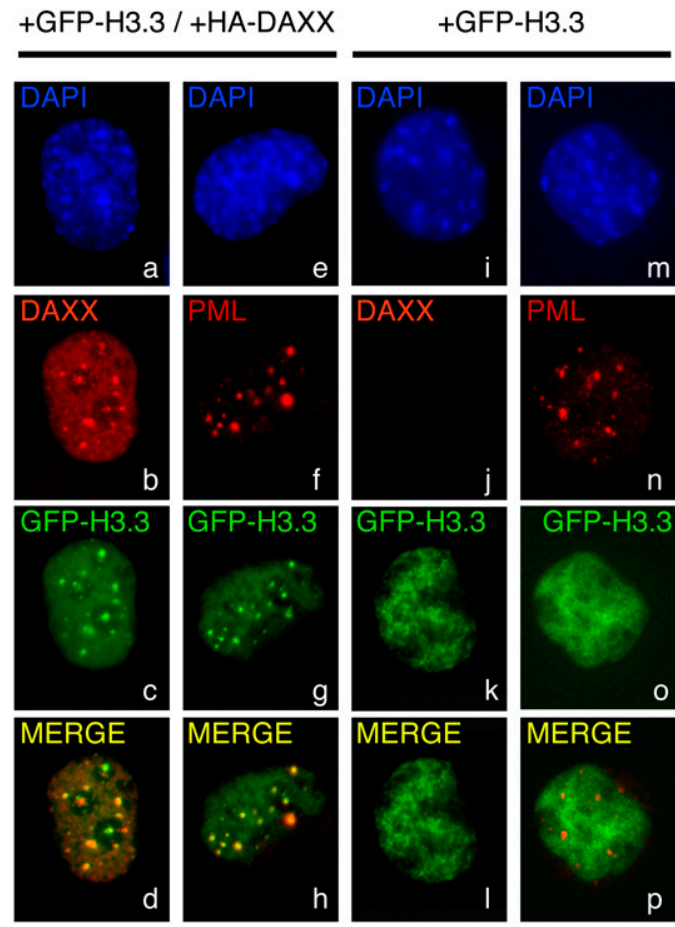

Figure 7. DAXX targets H3.3 to PML-NBs. Resting DAXX ${ }^{-/-}$ MEF cells were transiently transfected with GFP-tagged H3.3 expression vector (+GFP-H3.3) in combination $(a-h)$ or not $(i-p)$ with HA-DAXX expression vector (+HA-DAXX). Forty hours later, cells were supplemented with serum and were paraformaldehyde-fixed after an additional $8 \mathrm{~h}$. Distribution of HA-DAXX $(b, j)$ or endogenous PML $(f, n)$ in GFP-H3.3-positive cells was investigated by immunofluorescence staining using anti-HA or anti-PML antibody, respectively. $(a, e, i, m)$ DNA was stained with DAPI. $(d, h, l, p)$ Merged images correspond to the overlay of red (HA-DAXX or PML) and green fluorescence (GFP-H3.3).

\section{Discussion}

In this work, we studied in detail the mechanism of H3.3 deposition. We found that DAXX and the chromatin remodeling factor ATRX are crucial components of the H3.3 deposition machinery. Our data argue that DAXX functions as a chaperone involved in the replicationindependent deposition of H3.3.

\section{$D A X X$ is a histone chaperone specific for H3.3}

Although DAXX has been shown to be involved in apoptosis and transcriptional regulation, its physiological function remains poorly understood (Salomoni and Khelifi 2006). Our data unambiguously identify DAXX as a histone chaperone specific for H3.3, since (1) DAXX is associated stably with H3.3, but not with H3.1, in both the cytoplasm and the nucleus. This was demonstrated by immunopurifying both e-DAXX and e-H3.3 NCs and CCs. (2) DAXX contains a stretch rich in glutamic acid and aspartic acid residues embedded within an Rtt106-like domain, a feature that is shared by numerous histone chaperones, including the yeast Rtt106 chaperone (Huang et al. 2005), nucleoplasmin (Dutta et al. 2001), and FACT (Belotserkovskaya 
et al. 2003). We demonstrate that, in vitro, this DAXX domain interacts both strongly and preferentially with H3.3. (3) DAXX assembles tetramers onto naked DNA minicircles. The assembly is more efficient using tetramers that contain $\mathrm{H} 3.3$ than $\mathrm{H} 3.1$, a requirement for a chaperone specific for $\mathrm{H} 3.3$.

\section{DAXX is a H3.3 deposition factor}

DAXX is an essential gene in mouse development: The loss of DAXX results in extensive apoptosis and embryonic lethality (Michaelson et al. 1999; Ishov et al. 2004). This embryonic lethality could be explained by the failure to deposit or target $\mathrm{H} 3.3$ correctly. In agreement with this, the absence of $H 3.3 \mathrm{~A}$, one of the two genes encoding H3.3, resulted also in mouse embryonic lethality (Couldrey et al. 1999).

Our results show that the majority of $\mathrm{H} 3.3$ is in a complex with DAXX, and the purification of H3.3 from the $\mathrm{DAXX}^{-/-}$cells supports the idea that, under some circumstances, other chaperones can substitute for DAXX and bind H3.3. Indeed, the H3.3 complex is enriched with NASP in the absence of DAXX. Since NASP was found to be a chaperone for H3/H4 (Supplemental Fig. 11; Wang et al. 2008), it suggests that this protein acts as a buffer for an excess of free H3.3. In addition, CAF-1 is also recruited within the H3.3 complex in DAXX ${ }^{-1-}$ cells. This was quite surprising, since CAF-1 is considered to be a chaperone specific for H3.1 (Fig. 1B; Tagami et al. 2004). This indicates that a fraction of H3.3, in the absence of DAXX, could use the replication-dependent assembly pathway dedicated to H3.1. We hypothesize that DAXX prevents the association of $\mathrm{H} 3.3$ with CAF-1, thus not allowing the use of the replication-dependent assembly pathway by H3.3. Indeed, DAXX was found in both the cytoplasmic and the nuclear H3.3 complexes, whereas CAF-1 was present only in the nuclear H3.1 complex. Since DAXX associates with $\mathrm{H} 3.3$ in the cytoplasm, it is likely that the formation of a stable DAXX/H3.3 complex prevents further association of H3.3 with CAF-1.

\section{H3.3, DAXX, ATRX, and transcriptional regulation of pericentric chromatin}

Our results suggest that the deposition of $\mathrm{H} 3.3$ facilitates transcription from pericentric DNA repeats. In fact, although heterochromatin functions to silence transcription, transcripts spanning pericentric heterochromatin have been detected from fission yeast to mammals (Zaratiegui et al. 2007). While their role in mammals is still debated, these transcripts are required in fission yeast for the formation and maintenance of heterochromatin and for sister chromatid cohesion (Kato et al. 2005; Grewal and Jia 2007). Interestingly, depletion of mouse ATRX, the major partner of DAXX, leads to a defect in chromatid cohesion (Ritchie et al. 2008). Such a defect has not yet been reported for the DAXX-deficient cells, despite the description of shortened S-phase progression in these cells (Ishov et al. 2004). This could correspond to an alteration in heterochromatin formation, since replication of heterochromatin and S-phase progression are tightly interrelated (Quivy et al. 2008).
We still do not know the actual mechanism by which H3.3 facilitates transcription from pericentric DNA repeats. However, our results are in agreement with the recent report showing that down-regulation of $\mathrm{H} 3.3$ affects the induction of interferon- $\beta$-responsive genes (Tamura et al. 2009). This active role of H3.3 in transcription may be due, at least in part, to its ability to affect nucleosome stability, facilitating thereafter ejection of nucleosomes during the transcription process (Jin and Felsenfeld 2007).

One of the major DAXX-interacting partners is the ATPdependent chromatin remodeling factor ATRX (Fig. 6; Xue et al. 2003; Tang et al. 2004). ATP-dependent chromatin remodeling factors use the energy derived from ATP hydrolysis to modulate histone-DNA contacts (Hamiche et al. 1999). They appear to function not only in remodeling of existing nucleosomes, but also in histone deposition during chromatin assembly. We found that ATRX is present on pericentric DNA repeats together with DAXX and that the reduction of ATRX expression by siRNA affects both the transcription and DAXX-dependent deposition of $\mathrm{H} 3.3$ onto these repeats. This indicates that ATRX assists DAXX in the deposition of H3.3 by using the energy provided by ATP hydrolysis. In agreement with this, the Drosophila ATRX homolog XNP has been shown recently to interact genetically and cytologically with H3.3 (Schneiderman et al. 2009).

\section{DAXX and H3.3 in PML-NBs}

Human pericentric DNA repeats have been shown to colocalize with DAXX and ATRX within the PML-NBs (Luciani et al. 2006). Our data suggest that a fraction of H3.3 is targeted to PML-NBs in a DAXX-dependent manner. Moreover, the knockdown of DAXX strongly affected transcription of pericentric DNA repeats and histone H3.3 deposition. Taken together, these data tend to demonstrate that PML-NBs could serve as specific structures that target H3.3 to pericentric DNA repeats. We cannot exclude, however, that these structures are the sites of $\mathrm{H} 3.3$ storage that could modulate the supply and demand of this histone. Indeed, PML-NBs appear to accumulate numerous proteins implicated in the regulation of chromatin conformation (Bernardi and Pandolfi 2007). Future studies will be necessary to understand in detail the connection between PMLNBs and H3.3.

\section{HIRA and H3.3 deposition}

Purification of the complexes responsible for the H3.1 and H3.3 deposition from epitope-tagged H3-expressing HeLa cell lines has revealed that $\mathrm{H} 3.1$ is found mainly within a complex containing CAF-1, whereas H3.3 copurified with a complex containing the HIRA protein (Tagami et al. 2004). Using a similar approach of purification by double affinity, we found that H3.1 is indeed associated with CAF-1. In contrast, our data suggest that HIRA is not a stable component of H3.3 complex, since it is retained after the first antiFlag affinity, but is lost after the second anti-HA affinity (Supplemental Fig. 1). Rather, our results support the view that HIRA belongs to a histone-less complex containing ASF1a/b, Ubinuclein-1, Ubinuclein-2, and Cabin1. 
Given the data showing a connection between HIRA and H3.3 in various remodeling processes, we cannot refute that HIRA can somehow be in contact with H3.3. As mentioned before, it was found, for instance, that HIRA assembles H3.3 nucleosomes during decondensation of the Drosophila sperm pronucleus (Loppin et al. 2005). However, according to the same investigators (Loppin et al. 2005; Bonnefoy et al. 2007), HIRA is not required for deposition of H3.3 in embryos or adult Drosophila tissues. The role of HIRA in DNA synthesis-independent nucleosome assembly in human cells was also challenged recently by work by Galvani et al. (2008). This supports the view that the HIRA/H3.3 interaction could be cell or tissue context-dependent, and that multiple pathways are involved in the deposition of H3.3.

We cannot exclude from our results the existence of distinct and possibly redundant pathways of H3.3 deposition that could involve HIRA. We found, indeed, that DAXX is required for assembly of $\mathrm{H} 3.3$ nucleosomes onto pericentric DNA repeats, while it is only partially involved in this assembly onto the active gene DHFR (although addition of DAXX further stimulates the efficiency of this process by a factor of nearly two). The purification of the H3.3 complex from DAXX-depleted cells tends to support the idea that cells adapt to deposit H3.3 at least on $D H F R$. Alternatively, one can propose the existence of distinct deposition machineries, including the DAXX complex and the HIRA complex, which can function in specialized genomic regions. However, it remains to be understood how HIRA contacts H3.3, since the HIRA/ H3.3 interaction is probably not constitutive. Whether this interaction is regulated by post-translational modifications or by bridging proteins, such as ASF1, remains to be determined.

\section{H3 is associated with distinct complexes into the cell}

The biochemical purification of complexes containing unincorporated $\mathrm{H} 3.1$ or $\mathrm{H} 3.3$ offers new insights into the complexity of histone deposition pathways. H3 and H4 were found in complex with ASF1 in both the cytoplasm (the CC complex) (Fig. 2C) and the nucleus (the LNC complex) (Fig. 2C). Bearing in mind the previously reported data (English et al. 2006; Agez et al. 2007; Natsume et al. 2007), this complex should consist of a dimer of $\mathrm{H} 3$ and $\mathrm{H} 4$ and ASF1. In addition to the LNC, we identified in the nucleus another H3.1-H4 or H3.3-H4 complex, the HNC, which contains all four of the core histones in equimolar amounts (Fig. 2C). Our data do not us allow to discriminate whether this HNC comprises a full histone octamer (H2A$\mathrm{H} 2 \mathrm{~B}-\mathrm{H} 3-\mathrm{H} 4)_{2}$ or a heterotypic $\mathrm{H} 2 \mathrm{~A}-\mathrm{H} 2 \mathrm{~B}-\mathrm{H} 3-\mathrm{H} 4$ tetramer. We hypothesize that the HNC is the complex that is used to deposit histones onto DNA, and thus to assemble the nucleosome. If this is the case, the histones should be deposited as either a full histone octamer or a heterotypic tetramer, as was suggested recently for the Drosophila centromeric histone (Dalal et al. 2007). To our knowledge, there is as yet no compelling evidence against either possibility, since we still do not know the exact mechanism by which nucleosomes are assembled in vivo.

\section{Materials and methods}

\section{Cell lines}

H3.1, H3.3, DAXX, and HIRA proteins fused with C-terminal Flag- and HA-epitope tags (e-H3.1/e-H3.3/e-DAXX/e-HIRA) were stably expressed in cells by retroviral transduction (Ouararhni et al. 2006). The immortalized DAXX ${ }^{-/-}$MEF line was a kind gift of Dr. Gerd G. Maul (The Wistar Institute,) (Ishov et al. 2004).

\section{Antibodies}

Antibodies employed were as follows: monoclonal antibody antiFlag M2 (Sigma); anti-HA 9E (Roche Diagnostics); anti-H3.3 (H00003021-M01, Abnova); anti-PARP-1 (Alexis); anti-H3 CT, pan (05-928, Upstate Biotechnologies); anti-H2B (07-371, Upstate Biotechnologies); polyclonal anti-NASP (ProteinTech Group); and polyclonal antibodies from Santa Cruz Biotechnology antiDAXX (sc-7152), anti-ATRX (sc-15408), anti-CAF-1 p150 (sc10772), anti-CAF-1 p60 (sc-10982), and anti-PML (sc-18425). Anti-polII was produced by the IGBMC facility. Anti-Asfla is a kind gift of Dr. Carl Mann (Commissariat à l'énergie atomique de Saclay, France).

\section{Double-immunoaffinity purification}

Extracts were prepared using a modification of the Dignam protocol (Dignam 1990). Briefly, cells were lysed in hypotonic buffer (10 mm Tris- $\mathrm{HCl}$ at $\mathrm{pH} 7.65,1.5 \mathrm{~mm} \mathrm{MgCl}_{2}, 10 \mathrm{~mm} \mathrm{KCl}$ ) and disrupted by Dounce homogenizer. The cytosolic fraction was separated from the pellet by centrifugation at $4^{\circ} \mathrm{C}$. The nuclearsoluble fraction was obtained by incubation of the pellet in highsalt buffer (to get a final $\mathrm{NaCl}$ concentration of $300 \mathrm{mM}$ ). Tagged proteins were immunoprecipitated with anti-Flag M2-agarose (Sigma), eluted with Flag peptide $(0.5 \mathrm{mg} / \mathrm{mL})$, further affinitypurified with anti-HA antibody-conjugated agarose, and eluted with HA peptide $(1 \mathrm{mg} / \mathrm{mL})$. The HA and Flag peptides were first buffered with $50 \mathrm{mM}$ Tris-Cl (pH 8.5), then diluted to $4 \mathrm{mg} / \mathrm{mL}$ in TGEN 150 buffer (20 mM Tris at $\mathrm{pH} 7.65,150 \mathrm{mM} \mathrm{NaCl}, 3 \mathrm{mM}$ $\mathrm{MgCl}_{2}, 0.1 \mathrm{mM}$ EDTA, $10 \%$ glycerol, $00.01 \% \mathrm{NP} 40$ ), and stored at $-20^{\circ} \mathrm{C}$ until use. Between each step, beads were washed in TGEN 150 buffer. Complexes were resolved by SDS-PAGE and stained using the Silver Quest kit (Invitrogen).

Identification of proteins was carried out using an ion-trap mass spectrometer (ThermoFinnigan LTQ-XL) or by Taplin Biological Mass Spectrometry Facility (Harvard Medical School, Boston, MA).

For glycerol density gradient, samples were loaded onto a $4.5-\mathrm{mL}$ glycerol gradient $(17 \%-42 \%)$ and spun at $300,000 \mathrm{~g}$ in a Beckman SW50.1 rotor for $2 \mathrm{~h}$. Fractions were collected from the bottom of the tube. The approximate molecular weight of the different subcomplexes was estimated using the NativeMark molecular weight standard (Invitrogen).

\section{Immunofluorescence}

Immunofluorescence was done using standard procedures on a Leica DMR microscope (Leica) using a $63 \times 1.32$ NA oil immersion objective.

\section{Preparation of recombinant DAXX}

The full-length and deletions mutants of DAXX were PCRamplified from pcDNA3-HA-DAXX plasmid (a kind gift of Dr. Hsiu-Ming Shih, Academia Sinica, Taiwan) and subcloned into pGEX-5X.1 vector (GE Healthcare). GST fusion proteins were purified by standard methods. 


\section{Histones}

Human histones H3.1, H3.3, and H4 cDNA sequences were PCR-amplified by using Vent-DNA polymerase (New England Biolabs). All of the histones were cloned in a homemade bicistronic pET28b vector (Clontech). H3.1 and H3.3 were cloned at the NdeI-BamHI sites of pET28b in frame with an N-terminal His tag, while RBS-containing Flag-tagged $\mathrm{H} 4$ was cloned at the EcoRI-NotI sites. PCR-generated cDNA were sequenced for verification. BL21-CodonPlus-RIL cells (Stratagene) were routinely grown at $37^{\circ} \mathrm{C}$ on $\mathrm{LB}$ medium plus $0.1 \%$ glucose and selective pressure (kanamycin and chloramphenicol). Expression was induced at an $\mathrm{A} 600$ of 0.6 by addition of isopropyl $\beta$-Dthiogalactoside to a final concentration of $1 \mathrm{mM}$, and the culture was incubated for $2 \mathrm{~h}$ at $30^{\circ} \mathrm{C}$. Histones were purified using agarose anti-Flag M2 resin (Sigma). Purified histones were stored at $-80^{\circ} \mathrm{C}$ until use.

Epitope-tagged $(\mathrm{eH} 3.1 / \mathrm{eH} 3.3-\mathrm{H} 4)_{2}$ tetramers were prepared from HeLa cells expressing e-H3.1 and e-H3.3. Briefly, HeLa cell nuclei were digested with micrococcal nuclease to give predominantly mononucleosomes. Tagged mononucleosomes were next purified by the double-immunoaffinity method. Eluted material was bound to hydroxyapatite resin (Bio-Rad). Resin was washed successively with $0.65,0.9 \mathrm{M} \mathrm{NaCl}$, and bound $(\mathrm{H} 3-\mathrm{H} 4)_{2}$ tetramers were eluted with $2 \mathrm{M} \mathrm{NaCl}$.

\section{Protein-protein interactions}

GST fusion proteins immobilized on glutathione Sepharose were incubated for $1 \mathrm{~h}$ at room temperature with tagged $(\mathrm{H} 3-\mathrm{H} 4)_{2}$ tetramers or recombinant histones in TGN buffer $20 \mathrm{mM}$ Tris at $\mathrm{pH} 7.65,3 \mathrm{mM} \mathrm{MgCl}$, $0.1 \mathrm{mM}$ EDTA, $10 \%$ glycerol, $0.01 \%$ NP40) containing $250 \mathrm{mM} \mathrm{NaCl}$. Beads were then washed extensively in TGN containing $250 \mathrm{mM}, 500 \mathrm{mM}$, or $1 \mathrm{M} \mathrm{NaCl}$. Bound proteins were eluted in SDS sample buffer and fractionated on SDS-PAGE. Native histones were probed with anti-HA antibody, while recombinant histones were stained by Coomassie blue.

To study the interaction between GST-tNASP and histones, GST-tNASP was coexpressed with the bicistronic H3.1-H4 or H3.3-H4 in Escherichia coli strain BL21-CodonPlus-RIL-pLysS (Stratagene), as described (Shuaib et al. 2010).

\section{Transfection, synchronization, and RNAi}

MEF cells were transiently transfected using a standard calcium phosphate method. For synchronization, cells were starved for $48 \mathrm{~h}$ in DMEM containing 0.5\% FCS and were reinduced by the addition of $20 \%$ FCS, as described previously (Daury et al. 2006).

For siRNAs experiments, MEF cells were seeded onto six-well plates and transfected using Hiperfect (Qiagen) with a siRNA pool (Dharmacon) directed against $H 3.3 A$ and $H 3.3 B$ mRNA or an irrelevant siRNA ( $25 \mathrm{nM}$ final). Cells were harvested $72 \mathrm{~h}$ post-transfection for the assessment of the expression level of endogenous $H 3.3 A$ and $H 3.3 B$ mRNA, and of transcripts from pericentric repeats by real-time quantitative PCR analysis.

The sequences of the siRNA were as follows: $m H 3.3 A$ : ACGCGGAGAACGUGCUUAA, GCCAAACGUGUAACAAUUA, GUAAAGCACCCAGGAAACA, GUGAAGAAACCUCAUCGUU; mH3.3B: UGAGAGAGAUCCGUCGUUA, CCAGUUGGCUCGC CGGAUA, GAACCAAGCAGACCGCUAG, CACCAAGGCGGC UCGGAAA; mATRX: GGAAAGUGGAUCCGAAAUA, GUACAG AAAUCUCGCUCAA, AGAAAUGCAUCCUGCGCAA, AGAGA AGAAUGGCCGUAAA; $m H I R A$ : ACGCAUGUUCUCCGGCU UA, CUCUCAAGCUGAUGAUCGA, CUUGGGAUCCCGUU GGUAA, CAGUCACGGGUGUGGUCAA; irrelevant siRNA: GCCGGUAUGCCGGUUAAGUTT.
Retrotranscription and real-time quantitative PCR

Total RNAs were purified using standard methods and cDNA was synthesized by random priming. Real-time quantitative PCR was done with the QuantiTect SYBR green PCR kit (Qiagen) and a LightCycler apparatus (Roche Diagnostics). Primer pairs used were ACGTGCTTAAGAGTCCACTA and TTCCACTCG CAATCATATAC for H3.3A, GGCTGGTAACACAACACTAA and AGATGATGCTGGTGTGAATA for H3.3B, GACGACTT GAAAAATGACGAAATC and CATATTCCAGGTCCTTCAG TGTGC for pericentric repeats (Lehnertz et al. 2003), and CATGGCCTTCCGTGTTCCTA and TGCCTGCTTCACCAC CTTCT for GAPDH. Results were normalized to GAPDH.

\section{ChIP}

ChIP assays were performed as described in Drane et al. (2004). Primer pairs used were GACGACTTGAAAAATGACGAAATC/ CATATTCCAGGTCCTTCAGTGTGC for pericentric DNA repeats (Lehnertz et al. 2003), GGTACCAGGAAGACATGAGA/ TGTAGTGCCTTCCAGTAACC for DHFR, and CCAATGTGT CCGTCGTGGATCT/GTTGAAGTCGCAGGAGACAACC for pseudoGAPDH (Daury et al. 2006). Results were normalized to input DNA.

\section{Histone deposition assay}

Assay of histone deposition in the presence of the histone chaperone DAXX was performed using a negatively supercoiled DNA topoisomer -1 prepared from the 359 -bp hsp70 promoter. This fragment was purified from an EcoRI digest of the plasmid pBSK359x3 (Hamiche et al. 1999), ${ }^{32} \mathrm{P}$ end-labeled, and circularized in the presence of ethidium bromide (Hamiche and RichardFoy. 1999). Recombinant $(\mathrm{H} 3.1-\mathrm{H} 4)_{2}$ and $(\mathrm{H} 3.3-\mathrm{H} 4)_{2}$ tetramers $(100 \mathrm{ng} / \mu \mathrm{L})$ were purified as described above. $(\mathrm{H} 3.1-\mathrm{H} 4)_{2}$ and $(\mathrm{H} 3.3-\mathrm{H} 4)_{2}$ were mixed or not with equimolar amounts of DAXX in $20 \mathrm{mM}$ Tris- $\mathrm{Cl}(\mathrm{pH} 7.5), 50 \mathrm{mM} \mathrm{NaCl}$, and $3 \mathrm{mM} \mathrm{MgCl}_{2}$, and were incubated for $30 \mathrm{~min}$ at room temperature. Fifty nanograms of labeled circular DNA corresponding to topoisomer -1 was added to each mixture (at the indicated histone to DNA ratio, rw), incubated for $30 \mathrm{~min}$ at $37^{\circ} \mathrm{C}$, and analyzed on $4.5 \%$ native polyacrylamide gel $0.5 \times$ TG $(0.025 \mathrm{M}$ Tris, $0.192 \mathrm{M}$ glycine), run at room temperature. Control tetrasomes were assembled on circular DNA according to the "salt jump" method as described in Hamiche and Richard-Foy (1999).

\section{Acknowledgments}

We thank Dr. G.G. Maul, Dr. H.M. Shih, and Dr. C. Mann for the gift of materials, and Dr. S. Dimitrov and Dr. L. L. Pritchard for critical reading of the manuscript. This work was supported by grants from CNRS, INSERM, ANR number NT05-1_41978 (A.H.), ANR "EPIVAR" number 08-BLAN-0320-02 (A.H.), INCA (A.H.), the Association pour la Recherche sur le Cancer (A.H.), La Fondation pour la Recherche Medicale (A.H.), and La Ligue Nationale contre le Cancer (A.H.). K.O. acknowledges the Association pour la Recherche sur le Cancer for financial support.

\section{References}

Agez M, Chen J, Guerois R, van Heijenoort C, Thuret JY, Mann C, Ochsenbein F. 2007. Structure of the histone chaperone ASF1 bound to the histone H3 C-terminal helix and functional insights. Structure 15: 191-199.

Ahmad K, Henikoff S. 2002a. Histone H3 variants specify modes of chromatin assembly. Proc Natl Acad Sci 99: 16477-16484. 
Ahmad K, Henikoff S. 2002b. The histone variant H3.3 marks active chromatin by replication-independent nucleosome assembly. Mol Cell 9: 1191-1200.

Balaji S, Iyer LM, Aravind L. 2009. HPC2 and ubinuclein define a novel family of histone chaperones conserved throughout eukaryotes. Mol Biosyst 5: 269-275.

Banumathy G, Somaiah N, Zhang R, Tang Y, Hoffmann J, Andrake $M$, Ceulemans $H$, Schultz D, Marmorstein R, Adams PD. 2009. Human UBN1 is an ortholog of yeast Hpc2p and has an essential role in the HIRA/ASFla chromatinremodeling pathway in senescent cells. Mol Cell Biol 29: 758-770.

Belotserkovskaya R, Oh S, Bondarenko VA, Orphanides G, Studitsky VM, Reinberg D. 2003. FACT facilitates transcription-dependent nucleosome alteration. Science 301: 1090-1093.

Bernardi R, Pandolfi PP. 2007. Structure, dynamics and functions of promyelocytic leukaemia nuclear bodies. Nat Rev Mol Cell Biol 8: 1006-1016.

Bonnefoy E, Orsi GA, Couble P, Loppin B. 2007. The essential role of Drosophila HIRA for de novo assembly of paternal chromatin at fertilization. PLoS Genet 3: 1991-2006.

Chow CM, Georgiou A, Szutorisz H, Maia e Silva A, Pombo A Barahona I, Dargelos E, Canzonetta C, Dillon N. 2005. Variant histone H3.3 marks promoters of transcriptionally active genes during mammalian cell division. EMBO Rep 6: 354-360.

Couldrey C, Carlton MB, Nolan PM, Colledge WH, Evans MJ. 1999. A retroviral gene trap insertion into the histone 3.3A gene causes partial neonatal lethality, stunted growth, neuromuscular deficits and male sub-fertility in transgenic mice. Hum Mol Genet 8: 2489-2495.

Dalal Y, Furuyama T, Lindsay S, Henikoff S. 2007. Tetrameric structure of centromeric nucleosomes in interphase Drosophila cells. PLoS Biol 5: e218. doi: 10.1371/journal.pbio. 0050218.

Daury L, Chailleux C, Bonvallet J, Trouche D. 2006. Histone H3.3 deposition at E2F-regulated genes is linked to transcription. EMBO Rep 7: 66-71.

De Koning L, Corpet A, Haber JE, Almouzni G. 2007. Histone chaperones: An escort network regulating histone traffic. Nat Struct Mol Biol 14: 997-1007.

Dignam JD. 1990. Preparation of extracts from higher eukaryotes. Methods Enzymol 182: 194-203.

Drane P, Compe E, Catez P, Chymkowitch P, Egly JM. 2004 Selective regulation of vitamin $\mathrm{D}$ receptor-responsive genes by THIIH. Mol Cell 16: 187-197.

Dutta S, Akey IV, Dingwall C, Hartman KL, Laue T, Nolte RT, Head JF, Akey CW. 2001. The crystal structure of nucleoplasmin-core: Implications for histone binding and nucleosome assembly. Mol Cell 8: 841-853.

English CM, Adkins MW, Carson JJ, Churchill ME, Tyler JK. 2006. Structural basis for the histone chaperone activity of Asf1. Cell 127: 495-508.

Galvani A, Courbeyrette R, Agez M, Ochsenbein F, Mann C, Thuret JY. 2008. In vivo study of the nucleosome assembly functions of ASF1 histone chaperones in human cells. Mol Cell Biol 28: 3672-3685.

Green EM, Antczak AJ, Bailey AO, Franco AA, Wu KJ, Yates JR III, Kaufman PD. 2005. Replication-independent histone deposition by the HIR complex and Asf1. Curr Biol 15: 2044-2049.

Grewal SI, Jia S. 2007. Heterochromatin revisited. Nat Rev Genet 8: 35-46.

Hake SB, Garcia BA, Duncan EM, Kauer M, Dellaire G, Shabanowitz J, Bazett-Jones DP, Allis CD, Hunt DF. 2006.
Expression patterns and post-translational modifications associated with mammalian histone $\mathrm{H} 3$ variants. I Biol Chem 281: 559-568.

Hamiche A, Richard-Foy H. 1999. Characterization of specific nucleosomal states by use of selective substitution reagents in model octamer and tetramer structures. Methods 19: 457464.

Hamiche A, Sandaltzopoulos R, Gdula DA, Wu C. 1999. ATPdependent histone octamer sliding mediated by the chromatin remodeling complex NURF. Cell 97: 833-842.

Henikoff S, McKittrick E, Ahmad K. 2004. Epigenetics, histone $\mathrm{H} 3$ variants, and the inheritance of chromatin states. Cold Spring Harb Symp Quant Biol 69: 235-243.

Huang S, Zhou H, Katzmann D, Hochstrasser M, Atanasova E, Zhang Z. 2005. Rtt106p is a histone chaperone involved in heterochromatin-mediated silencing. Proc Natl Acad Sci 102: 13410-13415.

Ishov AM, Vladimirova OV, Maul GG. 2004. Heterochromatin and ND10 are cell-cycle regulated and phosphorylationdependent alternate nuclear sites of the transcription repressor Daxx and SWI/SNF protein ATRX. I Cell Sci 117: 3807-3820.

Jin C, Felsenfeld G. 2007. Nucleosome stability mediated by histone variants H3.3 and H2A.Z. Genes Dev 21: 1519-1529.

Kamakaka RT, Biggins S. 2005. Histone variants: Deviants? Genes Dev 19: 295-310.

Kato H, Goto DB, Martienssen RA, Urano T, Furukawa K, Murakami Y. 2005. RNA polymerase II is required for RNAi-dependent heterochromatin assembly. Science 309: 467-469.

Konev AY, Tribus M, Park SY, Podhraski V, Lim CY, Emelyanov AV, Vershilova E, Pirrotta V, Kadonaga JT, Lusser A, et al. 2007. CHD1 motor protein is required for deposition of histone variant H3.3 into chromatin in vivo. Science 317: 1087-1090.

Loppin B, Bonnefoy E, Anselme C, Laurencon A, Karr TL, Couble P. 2005. The histone H3.3 chaperone HIRA is essential for chromatin assembly in the male pronucleus. Nature 437: 1386-1390.

Lehnertz B, Ueda Y, Derijck AA, Braunschweig U, Perez-Burgos L, Kubicek S, Chen T, Li E, Jenuwein T, Peters AH. 2003. Suv39h-mediated histone H3 lysine 9 methylation directs DNA methylation to major satellite repeats at pericentric heterochromatin. Curr Biol 13: 1192-1200.

Lu J, Gilbert DM. 2007. Proliferation-dependent and cell cycle regulated transcription of mouse pericentric heterochromatin. J Cell Biol 179: 411-421.

Luciani JJ, Depetris D, Usson Y, Metzler-Guillemain C, MignonRavix C, Mitchell MJ, Megarbane A, Sarda P, Sirma H, Moncla A, et al. 2006. PML nuclear bodies are highly organised DNA-protein structures with a function in heterochromatin remodelling at the G2 phase. J Cell Sci 119: 25182531.

McDowell TL, Gibbons RJ, Sutherland H, O'Rourke DM, Bickmore WA, Pombo A, Turley H, Gatter K, Picketts DI, Buckle VJ, et al. 1999. Localization of a putative transcriptional regulator (ATRX) at pericentromeric heterochromatin and the short arms of acrocentric chromosomes. Proc Natl Acad Sci 96: 13983-13988.

McKittrick E, Gafken PR, Ahmad K, Henikoff S. 2004. Histone H3.3 is enriched in covalent modifications associated with active chromatin. Proc Nat1 Acad Sci 101: 1525-1530.

Michaelson JS, Bader D, Kuo F, Kozak C, Leder P. 1999. Loss of Daxx, a promiscuously interacting protein, results in extensive apoptosis in early mouse development. Genes Dev 13: $1918-1923$. 
Mito Y, Henikoff JG, Henikoff S. 2005. Genome-scale profiling of histone H3.3 replacement patterns. Nat Genet 37: 10901097.

Nakatani Y, Ogryzko V. 2003. Immunoaffinity purification of mammalian protein complexes. Methods Enzymol 370: 430444.

Natsume R, Eitoku M, Akai Y, Sano N, Horikoshi M, Senda T. 2007. Structure and function of the histone chaperone CIA/ ASF1 complexed with histones H3 and H4. Nature 446: 338341.

Ng RK, Gurdon JB. 2008. Epigenetic memory of an active gene state depends on histone H3.3 incorporation into chromatin in the absence of transcription. Nat Cell Biol 10: 102-109.

Ouararhni K, Hadj-Slimane R, Ait-Si-Ali S, Robin P, Mietton F, Harel-Bellan A, Dimitrov S, Hamiche A. 2006. The histone variant $\mathrm{mH} 2 \mathrm{~A} 1.1$ interferes with transcription by downregulating PARP-1 enzymatic activity. Genes Dev 20: 3324-3336.

Quivy JP, Gerard A, Cook AJ, Roche D, Almouzni G. 2008. The HP1-p150/CAF-1 interaction is required for pericentric heterochromatin replication and S-phase progression in mouse cells. Nat Struct Mol Biol 15: 972-979.

Richardson RT, Batova IN, Widgren EE, Zheng LX, Whitfield M, Marzluff WF, O'Rand MG. 2000. Characterization of the histone H1-binding protein, NASP, as a cell cycle-regulated somatic protein. I Biol Chem 275: 30378-30386.

Ritchie K, Seah C, Moulin J, Isaac C, Dick F, Berube NG. 2008. Loss of ATRX leads to chromosome cohesion and congression defects. J Cell Biol 180: 315-324.

Salomoni P, Khelifi AF. 2006. Daxx: Death or survival protein? Trends Cell Biol 16: 97-104.

Schneiderman JE, Sakai A, Golstein S, Ahmad K. 2009. The XNP remodeler targets dynamic chromatin in Drosophila. Proc Natl Acad Sci 106: 14472-14477.

Schwartz BE, Ahmad K. 2005. Transcriptional activation triggers deposition and removal of the histone variant H3.3. Genes Dev 19: 804-814.

Shuaib M, Ouararhni K, Dimitrov S, Hamiche A. 2010. HJURP binds CENP-A via a highly conserved $\mathrm{N}$-terminal domain and mediates its deposition at centromeres. Proc Natl Acad Sci 107: 1349-1354.

Steensma DP, Gibbons RJ, Higgs DR. 2005. Acquired $\alpha$-thalassemia in association with myelodysplastic syndrome and other hematologic malignancies. Blood 105: 443-452.

Tagami H, Ray-Gallet D, Almouzni G, Nakatani Y. 2004. Histone $\mathrm{H} 3.1$ and $\mathrm{H} 3.3$ complexes mediate nucleosome assembly pathways dependent or independent of DNA synthesis. Cell 116: 51-61.

Tamura T, Smith M, Kanno T, Dasenbrock H, Nishiyama A, Ozato K. 2009. Inducible deposition of the histone variant H3.3 in interferon-stimulated genes. I Biol Chem 284: 12217-12225.

Tang J, Wu S, Liu H, Stratt R, Barak OG, Shiekhattar R, Picketts DJ, Yang X. 2004. A novel transcription regulatory complex containing death domain-associated protein and the ATR-X syndrome protein. J Biol Chem 279: 20369-20377.

Wang H, Walsh ST, Parthun MR. 2008. Expanded binding specificity of the human histone chaperone NASP. Nucleic Acids Res 36: 5763-5772.

Wirbelauer C, Bell O, Schubeler D. 2005. Variant histone H3.3 is deposited at sites of nucleosomal displacement throughout transcribed genes while active histone modifications show a promoter-proximal bias. Genes Dev 19: 1761-1766.

Xue Y, Gibbons R, Yan Z, Yang D, McDowell TL, Sechi S, Qin J, Zhou S, Higgs D, Wang W. 2003. The ATRX syndrome protein forms a chromatin-remodeling complex with Daxx and localizes in promyelocytic leukemia nuclear bodies. Proc Natl Acad Sci 100: 10635-10640.

Yang X, Khosravi-Far R, Chang HY, Baltimore D. 1997. Daxx, a novel Fas-binding protein that activates JNK and apoptosis. Cell 89: 1067-1076.

Zaratiegui M, Irvine DV, Martienssen RA. 2007. Noncoding RNAs and gene silencing. Cell 128: 763-776. 


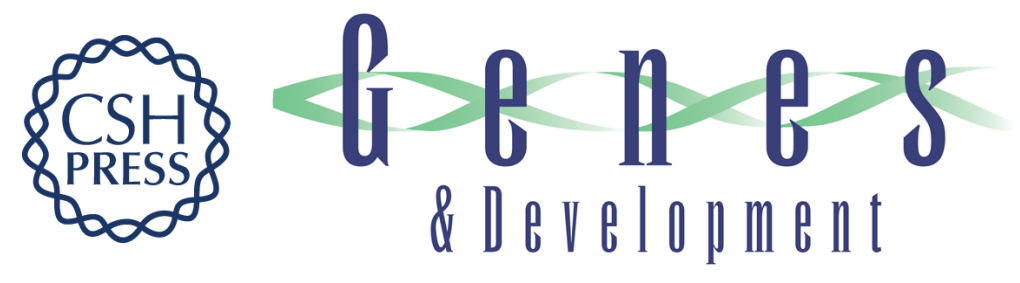

\section{The death-associated protein DAXX is a novel histone chaperone involved in the replication-independent deposition of $\mathrm{H3.3}$}

Pascal Drané, Khalid Ouararhni, Arnaud Depaux, et al.

Genes Dev. 2010, 24: originally published online May 26, 2010

Access the most recent version at doi:10.1101/gad.566910

\section{Supplemental http://genesdev.cshlp.org/content/suppl/2010/05/19/gad.566910.DC1 \\ Material}

Related Content New chaps in the histone chaperone arena

Eric I. Campos and Danny Reinberg

Genes Dev. July, 2010 24: 1334-1338

References This article cites 58 articles, 29 of which can be accessed free at:

http://genesdev.cshlp.org/content/24/12/1253.full.html\#ref-list-1

Articles cited in:

http://genesdev.cshlp.org/content/24/12/1253.full.html\#related-urls

\section{License}

Email Alerting

Service

Receive free email alerts when new articles cite this article - sign up in the box at the top right corner of the article or click here.

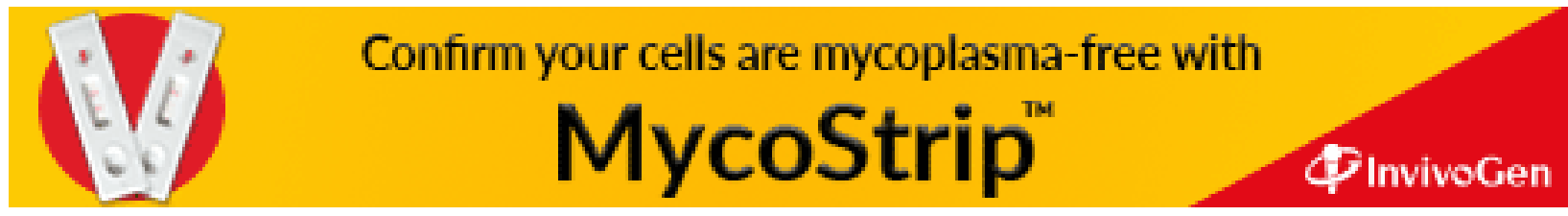

